Portland State University

PDXScholar

\title{
A Study of the Relationship Between Overt Behavior and: I) TAT Fantasy Aggression and the Stimulus Properties of Selected TAT Cards, II) Self-Report Measures of Aggression and Guilt, III) TAT Fantasy Aggression, Self-Report Measures and Personal Data
}

Christine Ruth Bauman

Portland State University

David James Leitner

Portland State University

Follow this and additional works at: https://pdxscholar.library.pdx.edu/open_access_etds

Part of the Applied Behavior Analysis Commons

Let us know how access to this document benefits you.

Recommended Citation

Bauman, Christine Ruth and Leitner, David James, "A Study of the Relationship Between Overt Behavior and: I) TAT Fantasy Aggression and the Stimulus Properties of Selected TAT Cards, II) Self-Report Measures of Aggression and Guilt, III) TAT Fantasy Aggression, Self-Report Measures and Personal Data" (1975). Dissertations and Theses. Paper 2354.

https://doi.org/10.15760/etd.2352

This Thesis is brought to you for free and open access. It has been accepted for inclusion in Dissertations and Theses by an authorized administrator of PDXScholar. Please contact us if we can make this document more accessible: pdxscholar@pdx.edu. 
AN ABSTRACT OF THE JOINT THESIS OF Christine Ruth Bauman and David James Leitner for the Master of Science in Psychology presented July 22, 1975.

Title: A Study of the Relationship Between Overt Behavior and:

I) TAT Fantasy Aggression and the Stimulus Properties of Selected TAT Cards.

II) Self-Report Measures of Aggression and Guilt.

III) TAT Fantasy Aggression, Self-Report Measures and Personal Data.

APPROVED BY MEMBERS OF THE THESIS COMMITTEE:
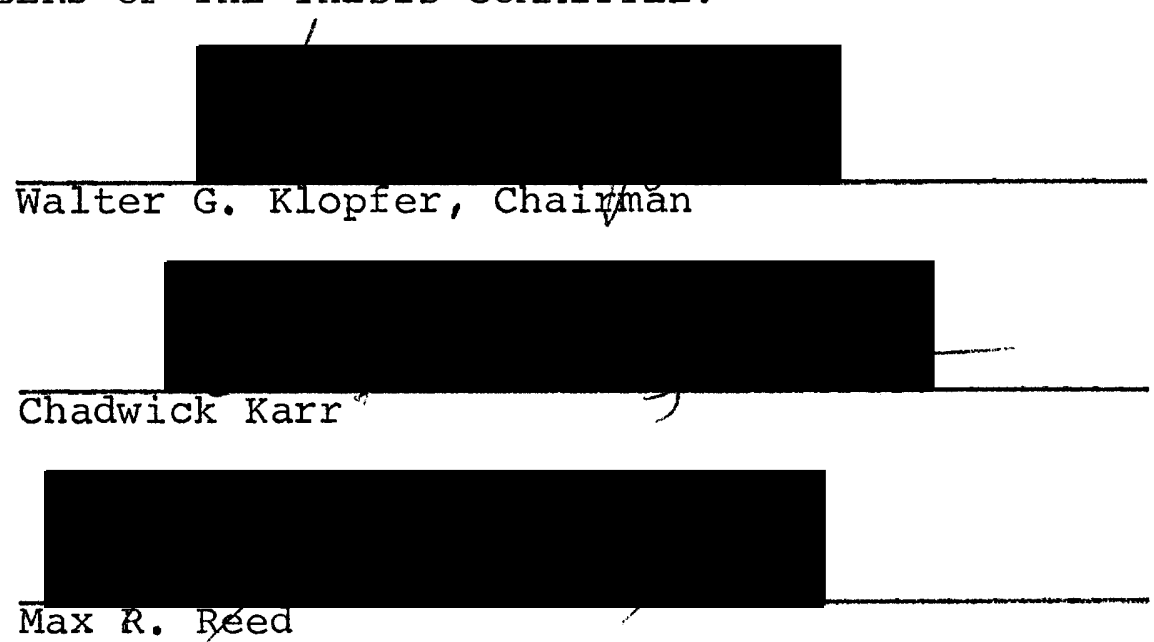

Past research has shown that there are many. factors that influence projective test responses. This is especially true of the Thematic Apperception Test (TAT). Certain variables that have been found to influence the TAT response were studied in this experiment. These variables included the 
subjects' scores on purported measures of the personality trait of aggression, and various parameters of the TAT cards themselves.

This experiment included three studies which investigated the relationship between test measures of aggression and aggressive behavior. The three studies were conducted concurrently using the same subject population: forty-two male inmates at the oregon state Penitentiary. They were divided into two groups of aggressiveness according to the crime they had committed; 21 inmates had committed aggressive crimes and 21 inmates had committed non-aggressive crimes. The subjects wrote stories for eight TAT cards; completed a questionnaire including items on aggression, guilt, and defensiveness; and provided personal information such as age, educational level, and amount of time in prison.

Study I was concerned with the effect of the stimulus TAT cards on the relationship between TAT stories and overt aggression. The eight TAT cards selected varied on two stimulus properties: ambiguity (variability of response) and cue relevance (clarity of a card with respect to a specific behavior). Thus, there were four conditions: high cue relevance/high ambiguity, high cue relevance/low ambiguity, low cue relevance/high ambiguity, and low cue relevance/low ambiguity.

The results showed that high cue relevance cards differentiated aggressive from non-aggressive subjects while low 
cue relevance cards did not. High cue relevance cards and high ambiguous cards elicited more aggressive themes than the low levels of cue relevance and ambiguity. It was concluded that the stimulus properties of the cards do influence the TAT response.

Study II examined the relationships between three measures of aggression (self-report, TAT fantasy and crime committed) and a self-report guilt score. It was predicted that the guilt score would be inversely correlated to all three measures of aggression, that the self-report aggression and TAT fantasy aggression scores would be positively correlated to each other and that these two aggression scores would both be positively correlated to crime committed.

A significant negative correlation was found between the self-report Guilt and Aggression scores. A significant correlation was found between crime committed and TAT fantasy only on the high relevant cards.

The results seem to indicate the Zaks and Walters Aggression Scale was not able to differentiate aggressive and non-aggressive prisoners. There was evidence that this Aggression scale may measure a willingness to admit to aggressive feelings rather than a behavioral tendency. Also, there were better correlations among the self-report measures than between any of the measures and overt behavior. Study III investigated the effect of a variety of stimulus conditions on the prediction of crime committed. A 
stepwise discriminant analysis was used on the variables included in studies I and II and age, education and past times spent in prison. The results seemed to indicate that the best predictor of group membership was the aggression score for the high relevant TAT cards. After the sixth step, the analysis provided a formula which successfully predicted group membership of $74 \%$ of the subjects. However, the $\underline{F}$ values were low $(p, .05)$ and it is doubtful that this formula would predict group membership this accurately in a cross validation study. 
A STUDY OF THE RELATIONSHIP BETWEEN OVERT BEHAVIOR AND:

I) TAT FANTASY AGGRESSION AND THE STIMULUS PROPERTIES OF SELECTED TAT CARDS.

II) SELF-REPORT MEASURES OF AGGRESSION AND GUILT.

III) TAT FANTASY AGGRESSION, SELF-REPORT MEASURES AND PERSONAL DATA.

\author{
by \\ CHRISTINE RUTH BAUMAN \\ and \\ DAVID JAMES LEITNER
}

A thesis submitted in partial fulfillment of the requirements for the degree of

\author{
MASTER OF SCIENCE \\ in \\ PSYCHOLOGY
}

Portland State University

1975 
TO THE OFFICE OF GRADUATE STUDIES AND RESEARCH:

The members of the Committee approve the thesis of:

Christine Ruth Bauman and David James Leitner presented July 22, 1975.
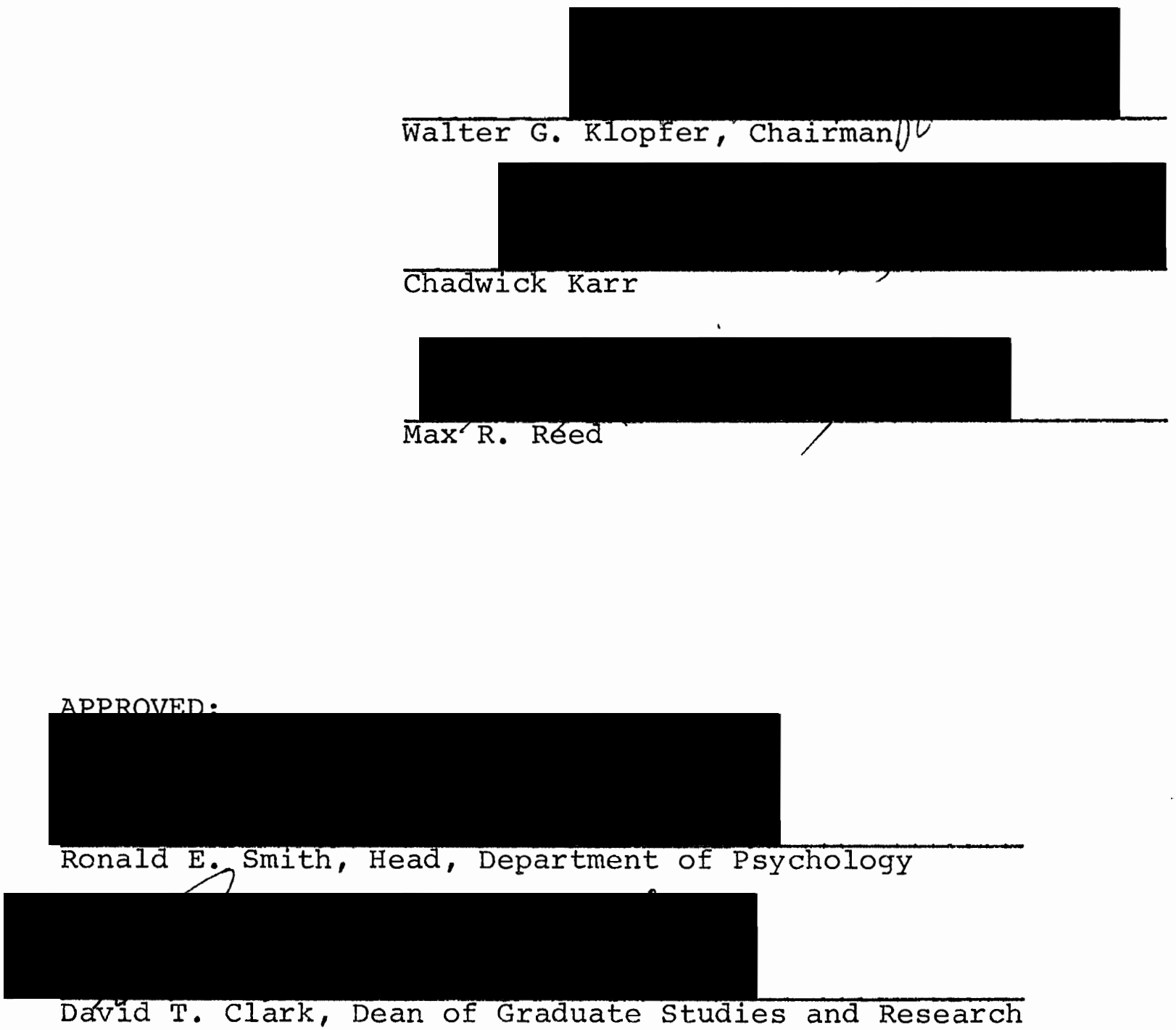


\section{ACKNOWLEDGMENTS}

In addition to our committee we would like to thank several people for their help with various aspects of this project. We thank Quentin Clarkson and James Paulson for their statistical assistance; Charles Schwenk and Robert Spencer for their help in scoring the tests; and Alison Berman and James Kushmuk for both research assistance and moral support. Also we express our appreciation to the persons who participated in this study, with special thanks to the staff persons without whose cooperation this project would have been impossible: John Cavender and Steven Gassner at the Oregon State Penitentiary and Curt Fiesel at the Oregon State Women's Correctional Institution.

In addition to the persons named above, we thank our housemates, friends and relatives who gave support and assistance. We also thank a number of people who indirectly assisted in this writing: Carl Rogers, Fred Nietzche, Kilgore Trout, Christy Bauman and Dave Leitner. 
TABLE OF CONTENTS

PAGE

ACKNOWLEDGMENTS • • • • • • • • • • • • • • • • iii LIST OF TABLES • • . • • • • • • • • • • • $\mathrm{v} i$

CHAPTER

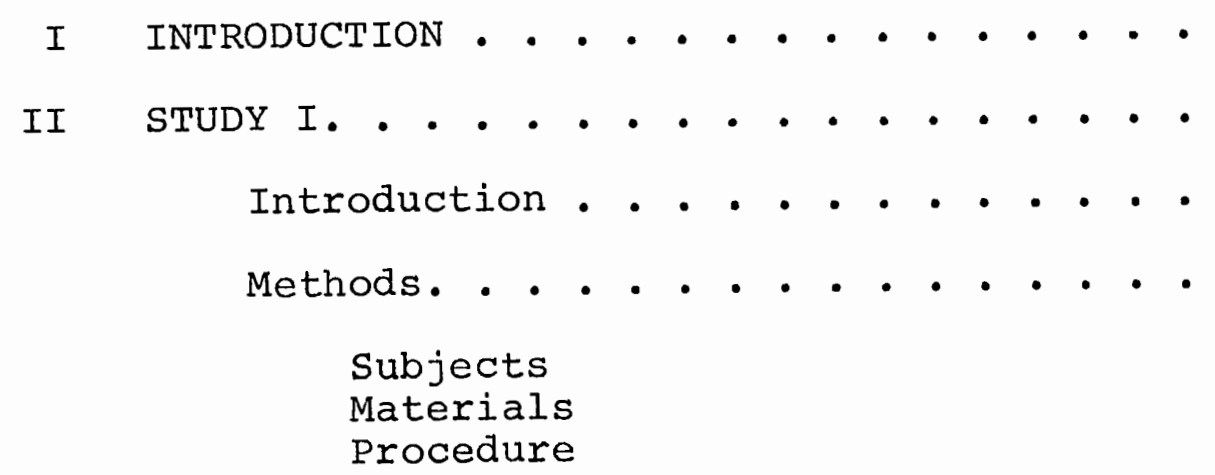

Results. • . . . . . . . • •

Discussion . . . . . . . . . .

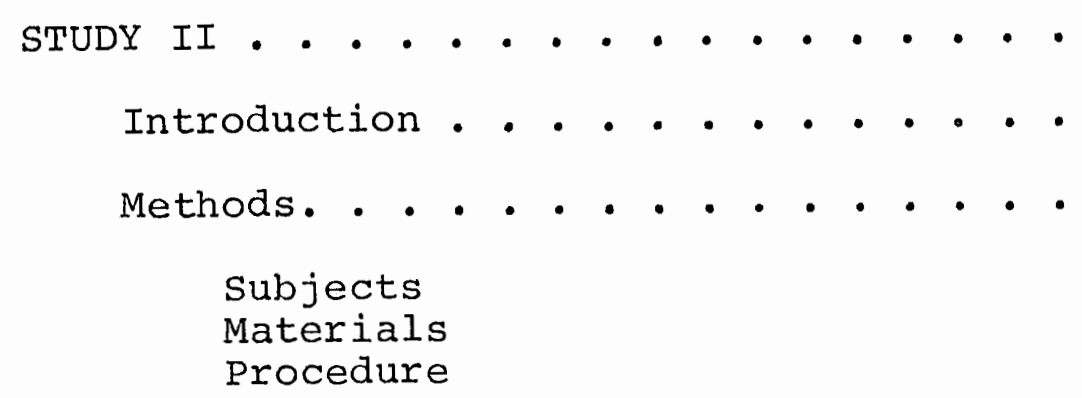

Subjects

Materials

Procedure

Results. • . . . . . . . . •

Hypothesis 1

Hypothesis 2

Hypothesis 3

MMP I $\mathrm{K}$ Score

Discussion . . . . . . . . . • 

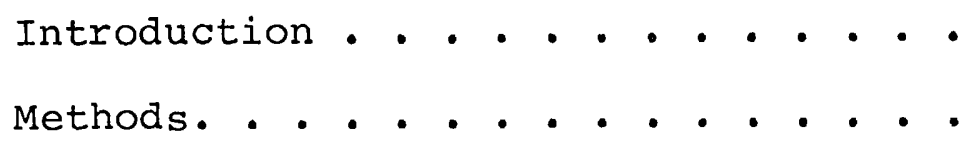

subjects

Materials

Procedure

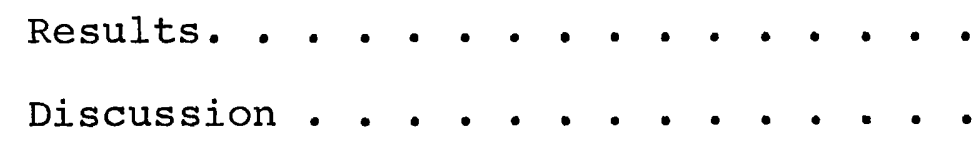

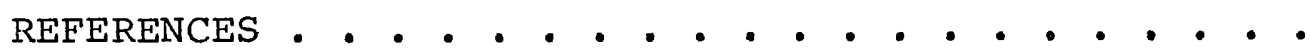




\section{IIST OF TABLES}

TABLE

PAGE

I Means and Standard Deviations for Each

Stimulus Condition for Aggressive

and Non-aggressive Subjects. . . . .

II A $2 \times 2 \times 2$ Analysis of Variance: Test of

Significance • • • • • • • • • •

III Percentage of Aggressive and Non-aggressive

Groups Agreeing with Each Item of the

Zaks and Walters Aggression Scale. • •

IV Mean Score and Range for Aggressive and Non-aggressive Groups on Each of the Four Measurements Used in Study II. .

$\mathrm{V}$ Mean Value and Range for the Aggressive and Non-aggressive Groups on the Personal Data Gathered for Study III . . 


\section{CHAPTER I}

\section{INTRODUCTION}

It has long been established that there are a myriad of variables which can influence a test response. This is true for both the more standardized objective tests and the less structured projective tests of personality assessment. For example, the social desirability response set (the subject's tendency to answer in a socially desirable manner) is a methodological variable of objective tests that can produce disturbing effects on inferences concerning the subject's personality. Researchers attempt to control methodological variables such as the social desirability response set so that the subject's response reflects his actual behavior or personality trait (Tyler, 1963): Unlike the standardized objective personality tests, projective tests permit a relatively, large degree of freedom for the subject in making his response. However, like objective tests, projective tests are also characterized by problems that influence the test response. In order to understand the projective test response, so that it reflects the subject's behavior, certain variables that have been found to influence the projective response must be carefully studied. One of the most frequently used projective tests, yet 
the subject's attitude toward a personality trait and the stimulus situation on the relationship between the TAT response and overt behavior. The personality trait that was investigated is aggression. The importance of studying a behavior as prevalent as aggression is well documented. For example, Freud was convinced that aggression was as an important motive as sex. Cofer and Appley (1964) state of aggression:

Most of the early theorists included an instinct for this kind of behavior in their lists of instincts, and the prevalence of aggression, hostile actions-ranging from war to sibling rivalry--has maintained the status in most motivational systems of some concept or entity that refers to aggression. (p. 744)

An interesting example of the unreasonable nature of aggression is reported by Lorenz (1963) where he imagines an absolutely unbiased observer on another planet examining human behavior:

If we suppose our extraneous observer to be a being of pure reason, devoid of instincts himself and unaware of the way in which all instincts in general and aggression in particular can miscarry, he would be at a complete loss how to explain history at all. The ever current phenomena of history do not have reasonable causes. - . Unreasoning and unreasonable human nature causes two nations to compete, though no economic necessity compels them to do so: it induces two political parties or religions with amazingly similar programs of salvation to fight each other bitterly, and it impels an Alexander or Napoleon to sacrifice millions of lives in his attempt to unite the world under his scepter. (pp. 228-9)

Thus, although aggression has been intensively studied, it is still not completely understood.

The TAT is only one of many ways of studying aggression. Aggression can be measured by sociometric ratings where 
subjects rank peers in relation to other peers on the dimension of aggressiveness. Aggression can also be measured by objective paper and pencil tests, observer ratings and interviews. However, Buss (1961) points out that the TAT can be used effectively to compare TAT aggression scores to the subject's known aggressiveness. The present experiment investigated the influence of the subject's attitude toward aggression and the stimulus situation (TAT cards) on the relationship between TAT aggression scores and overt behavior.

Many studies have investigated the relationship between the TAT response and aggression (Mussen and Naylor, 1954; Stone, 1956; Kagan, 1959). Some studies have investigated the influence of the stimulus situation, the cards, on the relationship between TAT aggression and overt aggression (Eron, 1950, 1953; Murstein, 1965; Kaplan, 1967). Several studies have looked at other possible factors that influence the relationship between TAT aggression and overt behavior. Two such factors that are investigated in the present experiment are the subject's aggressive self-concept (Murstein, 1965, 1968) and guilt over aggression (Saltz and Epstein, 1963; James and Mosher, 1967). (The results of these studies are reported later in the text.)

A problem area that one confronts when reading research in this area is that the terms aggression and hostility are used interchangeably. This experiment investigates aggressive behavior. The term aggression is defined in this experiment, 
according to Wilds' (1973) definition, as behavior that has the intent to cause harm to people or the destruction of property. It was operationally defined as follows: the subject's aggressiveness or non-aggressiveness was determined by the type of crime committed by inmates at the oregon State Penitentiary in Salem, Oregon. Crimes of violence (murder, rape, kidnapping, assault, robbery, etc.) were considered aggressive while non-violent crimes (embezzlement, burglary, forgery, etc.) were considered non-aggressive. (See Appendix A for Wilds' complete classification system.)

This experiment includes three studies concerned with investigating the relationship between test measures of aggression and aggressive behavior. Study I was concerned with the effect of the stimulus, the TAT cards, on the relationship between TAT stories and overt aggression. This study is similar to the one done by Kaplan (1967) except that the present study used the overt behavioral criterion of aggression as defined above while Kaplan classified subjects on a selfreport measure of aggression.

Study II investigated the subject's attitude toward aggression, and guilt feelings over aggression, and their relationship to TAT aggression scores and overt aggressive behavior. This study is similar to one done by Saltz and Epstein (1963) except that Saltz and Epstein divided the subjects on the basis of self-report measures and used specially constructed TAT-like cards rather than Murray's TAT 
cards.

Study III combines the data from Studies I and II. It was hoped that with the data from both studies plus some additional information, it would be possible to differentiate more accurately those persons who committed crimes of violence from those subjects who committed non-violent crimes. The study also tested Mischel's (1971) assumption that the stimulus environment (i.e., type of test, or stimulus pull of a particular TAT card) is probably more important than the subject's disposition toward a personality trait (i.e., aggression) in determining the subject's behavior. 
CHAPTER II

STUDY I

This study investigates a question which has long interested clinical psychologists: the relationship of the aggressive content on the TAT test to overt aggression. It is particularly interesting because it can serve as a paradigm for the more basic question of the relationship of projective techniques to overt behavior. Iindzey (1961) states that the basic assumption of a projective test, such as the TAT, is:

If an individual is presented with a stimulus situation permitting variable responses, the particular response he emits will reflect his characteristic patterns and tendencies to response. (p. 146)

In other words, a person's response is determined by their personality characteristics. The present study is a test of that assumption.

There is much disagreement concerning the relationship of TAT themes to overt aggression. Megargee and Cook (1956) report after a review of the literature that one conclusion that can be drawn is:

Authorities differ as to the relationship which should be expected between projective test scores and overt behavior, some holding that it should be direct and others that it should be inverse. (p. 48)

However, Lindzey and Tejessey (1956) state that most studies found little empirical support for significant inverse 
relationships between projective tests and overt aggression. It seems that an area that needs investigation in interpreting TAT themes is to determine the conditions under which inferences based on TAT themes directly relate to overt behavior. There is a diversity of findings relating TAT aggression to overt behavior. Many studies report a direct relationship only if certain variables are considered. For example, Saltz and Epstein (1963) found a positive relationship between selfreported and TAT aggression on subjects high in self-reported guilt over hostility. Murstein (1968) found that subjects who had hostile self-concepts improved the relationship between overt and TAT aggression. Another such variable is the stimulus itself, the TAT cards (Kagan, 1956; Murstein, 1965, 1968; James and Mosher, 1967; and Kaplan, 1967).

Each of the TAT cards seem to elicit different types of responses since each picture depicts a different scene. Eron (1950) in constructing normative data for the TAT cards stated:

It is obvious that the TAT pictures themselves call forth certain kinds of stories with characteristic emotional tone and that they are as important as the clinical classification of the subject in determining what kind of response he will make. . . It has been felt that each individual picture has its own stimulus properties which evoke themes, identifications, feelings, etc., which are peculiar to it and which differ from those elicited by other pictures. (p. 25)

The importance of determining the cards' influence on TAT themes before making inferences about a subject's personality is emphasized by Eron (1953).

It is important that the experimenter not be misled 
in his interpretations by responses which seem unusual

to the "naked eye" but which on more careful investigation are found to be common among subjects of similar age and status. (p. 269)

In other words, the stimulus properties of the cards play an important role in determining the subject's response, and it is necessary to determine the cards' influence before inferences can be made about the subject's personality.

There are two stimulus properties of the TAT cards which have been empirically investigated. They are cue relevance (Saltz and Epstein, 1963; Stone, 1956; Murstein, 1965; James and Mosher, 1967), and ambiguity (Kagan, 1959; Murstein, 1963; and Kaplan, 1967). There is some confusion among the definitions of cue relevance and ambiguity, which makes comparison of studies very difficult. For example, Kagan (1959) investigated the influence of ambiguity of the TAT cards on the relationship between overt and TAT aggression. However, Kagan's definition of ambiguity is similar to Murstein's (1963) definition of cue relevance. Murstein makes a distinction between cue relevance and ambiguity. He defines cue relevance as the value or clarity of a stimulus with respect to a specific behavior, while ambiguity is defined as the uncertainty of meaning, categorization, or the variability of response. Murstein's definitions are used in the present study.

The experimental design generally used in determining the influence of ambiguity and/or cue relevance involves the 
discrimination of aggressive from non-aggressive subjects, which have been categorized by self-report measures, sociometric questionnaires, or observer ratings. The subjects are asked to write stories about TAT cards which differ in their levels of ambiguity and/or cue relevance. The thematic stories are then scored to determine what level of ambiguity and/or cue relevance is best at discriminating aggressive from nonaggressive subjects.

Inconsistent findings have been reported as to what levels of ambiguity and cue relevance are best at differentiating aggressive from non-aggressive subjects. Murstein (1965) found that cards of low and medium cue relevance had greater sensitivity in discriminating hostile from friendly subjects. However, Murstein defined hostility using the subjects' self rating in relation to peers on the dimension of friendliness. He assumed that low ratings on the friendliness dimension implied hostility, which this experimenter believes to be an unwarranted assumption. The subjects might not have represented a true sample of the friendlinesshostility dimension. Saltz and Epstein (1963) also found that low relevance cards were better in discriminating hostile from non-hostile subjects (determined by self-report questionnaire) than high relevance cards. It is impossible to compare these results with Murstein's results since Saltz and Epstein used a specially constructed TAT-like test. Contrary findings have been reported by Kagan (1959). 
He found that cards with high stimulus relevance differentiated persons who were high and low on overt aggression, supporting the principle that one can maximize the predictive accuracy of the cards by increasing the similarity of the thematic cues to the criterion situation characterized by aggression. (Kagan refers to the ambiguity and "content pull," i.e., cue relevance, as equivalent in his investigation, which makes it difficult to determine to what stimulus property he refers. However, Kagan's use of the term, ambiguity, seems closer to Murstein's definition of cue relevance than ambiguity.) James and Mosher (1967) investigated the relevancy of the cards and found that high relevance cards predicted hostility (obtained by sociometric questionnaire), whereas the low relevance cards did not predict hostility. However, James and Mosher constructed their own TAT cards which makes comparison with other research evidence difficult. Kaplan (1967) was the first to investigate the interaction of cue relevance and ambiguity (using Murstein's definitions) of TAT cards in differentiating high and low self-reported hostile groups. He found that cards of high cue relevance were able to differentiate hostile from nonhostile subjects regardless of the degree of ambiguity. He also found that high ambiguous cards elicited more aggressive themes than low ambiguous cards regardless of the level of self-reported hostility or the degree of cue relevance. This is consistent with Murstein's (1963) conclusion from a review 
of the literature that increasing the level of ambiguity does not improve the differentiation of hostile from non-hostile subjects.

The present study is similar to Kaplan's in that the influence of both ambiguity and cue relevance on the relationship between overt and fantasy aggression was investigated. Two levels of both ambiguity and cue relevance were determined, as in Kaplan's study, from norms developed by Eron. Kaplan used Eron's (1953) female norms, while the present study used Eron's (1950) male norms. Murstein, et al. (1961) also developed norms on the stimulus properties of the TAT cards. The present study chose to use Eron's norms in order to maintain the similarity with Kaplan's study and because it was possible to rate the cards for both ambiguity and cue relevance. It must be noted that the two systems differ on some of the levels of the stimulus properties of the cards.

On the basis of the evidence reported, the following hypotheses were formulated:

1) Overt aggressive behavior, as defined by the subjects' crimes, is correlated to the amount of aggressiveness found in the TAT themes.

2) High cue relevance cards differentiate aggressive from non-aggressive subjects better than low relevance cards.

3) High ambiguous cards will elicit more aggressive themes than low ambiguous cards. 


\section{Methods}

Subjects

The subjects were male prisoners at the oregon state Penitentiary: 21 who had committed crimes of violence (murder, rape, robbery, etc.) and 21 who had committed crimes of nonviolence (forgery, embezzlement, burglary, etc.). One of the conditions that the non-aggressive subjects had to meet was that they had not previously committed a crime of violence.

\section{Materials}

TAT cards were chosen on the basis of cue relevance and ambiguity similar to Kaplan (1967). High cue relevance cards met the following criterion: the more dominant themes in a normative sample (Eron, 1950) were ones of aggression. Low relevance cards had to have no aggressive theme that appeared with greater than $10 \%$ frequency in Eron's normative samples.

Ambiguity was determined, as in Kaplan, by reference to the relative frequency of themes in Eron's (1950) norms. Cards of low ambiguity were defined as those in which the dominant theme appeared with greater than $35 \%$ frequency in the responses of the normative groups, this theme having an appearance rate of at least $20 \%$ greater frequency than the next most popular theme. Highly ambiguous cards required that there be no theme with greater than $35 \%$ frequency of appearance with the two most dominant themes being within 
$20 \%$ of each other. In this manner eight cards were chosen for the experimental stimuli. Cards 20 and 15 were high relevance/high ambiguity; $8 \mathrm{BM}$ and $11^{1}$ were high relevance/low ambiguity; $2 \mathrm{BM}$ and 14 were low cue relevance/high ambiguity; and $9 \mathrm{BM}$ and $7 \mathrm{BM}$ were low cue relevance/low ambiguity.

Procedure

The subjects were randomly assigned to one of two rooms. Instructions concerning the task were given the subjects (see Appendix B). The subjects were then asked to read and sign a form stating the voluntary nature and confidentiality of their responses (see Appendix C). The groups were then shown slides of the appropriate eight stimulus cards in random order. The TAT responses were scored using the TAT Agressive Content Scale developed by stone (1956). In the study by stone, the TAT Agressive Content Scale was able to differentiate assaultive from non-assaultive army prisoners.

Results

Three statistical tests were used. First, a one-way $\underline{t}$ test was performed for the first hypothesis. Second, a $2 \times 2 \times 2$ analysis of variance (repeated measures on two factors) was performed for the second and third hypotheses. The subjects' responses to cards with combinations of high and low ambiguity

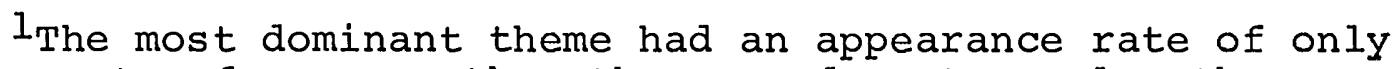
17.3\% greater frequency than the second most popular theme. 
and cue relevance were the repeated measures in the design, while the subject's overt behavior was the third variable. The number of aggression-related themes were scored for each of the subject's eight responses to the TAT cards. Each of the subject's eight scores were then summed into one of four conditions (two scores per condition). The conditions were high cue relevance/high ambiguity, high cue relevance/low ambiguity, low cue relevance/high ambiguity, and low cue relevance/low ambiguity. Table I shows the mean number of aggressive themes for each stimulus condition across subjects.

TABLE I

MEANS AND STANDARD DEVIATIONS FOR EACH STIMULUS CONDITION FOR AGGRESSIVE

AND NON-AGGRESSIVE SUBJECTS

\begin{tabular}{|c|c|c|c|c|c|c|}
\hline & & \multirow[b]{3}{*}{ Ambiguity } & \multicolumn{4}{|c|}{ Overt Behavior Criterion } \\
\hline & & & \multicolumn{2}{|c|}{ Aggressive } & \multicolumn{2}{|c|}{ Non-aggressive } \\
\hline & & & Mean & S.D. & Mean & $S \cdot D \cdot$ \\
\hline \multirow{4}{*}{$\begin{array}{l}\text { Cue } \\
\text { Rele- } \\
\text { vance }\end{array}$} & \multirow{2}{*}{ High } & High & 3.26 & 1.87 & 2.23 & 1.29 \\
\hline & & Low & 2.40 & 1.60 & 1.59 & 1.03 \\
\hline & \multirow{2}{*}{ Low } & High & 0.83 & 1.25 & 0.78 & 1.00 \\
\hline & & Low & 0.88 & 1.36 & 1.00 & 1.09 \\
\hline
\end{tabular}

Third, an interrater reliability score of $\underline{r}=.80$ was determined by correlation agreement (Pearson product-moment correla- 
tion) between two naive judges ${ }^{2}$ for a random sample of 19 subjects who produced a total of 152 stories.

The first hypothesis which stated that the amount of thematic aggressiveness would be correlated with the subject's overt behavior was not supported. A one-way $t \underline{t}$ test was performed which yielded a $t$ value of $1.32, p L .10$.

The analysis of variance, Table II, shows two main effects: cue relevance $(\underline{F}(1,40)=49.03, \underline{p}(.001)$ and ambiguity $(\underline{F}(1,40)=6.30, \underline{\mathrm{p}} L .025)$ and significant interaction effects for Groups $x$ Cue Relevance $(\underline{F}(1,40)=4.94, p \leq .05)$ and for Cue Relevance $\mathrm{x}$ Ambiguity $(\underline{\mathrm{F}}(1,40)=6.87, \mathrm{p} L .025)$. The results support the second hypothesis that high cue relevance cards are better able to differentiate aggressive from non-aggressive subjects, while low cue relevance cards were not able to differentiate the two groups (see Appendix D). The Group $x$ Cue Relevance interaction was significant regardless of the level of ambiguity.

The data also support the third hypothesis that high ambiguous cards elicited more aggressive themes than low ambiguous cards. However, ambiguity was not able to differentiate the aggressive from the non-aggressive subjects.

In addition to the hypotheses, the results found a cue Relevance $\mathrm{x}$ Ambiguity interaction. It showed that high. ambiguous cards elicited more aggressive themes than low

2 Two graduate students who were not familiar with the study's hypotheses nor with the subject's group membership. 
TABLE II

A $2 \times 2 \times 2$ ANALYSIS OF VARIANCE: TEST OF SIGNIFICANCE

\begin{tabular}{|c|c|c|c|c|c|}
\hline Source & SS & $d f$ & $\underline{\mathrm{ms}}$ & $\underline{E}$ & $\underline{p}$ \\
\hline Tota 1 & 414.875 & 167 & - & - & - \\
\hline Between S's & 148.128 & 41 & - & - & - \\
\hline Groups & 8.149 & 1 & 8.149 & 2.329 & ns \\
\hline Error $_{b}$ & 139.976 & 40 & 3.499 & - & - \\
\hline Within $S^{\prime} \mathbf{s}$ & 266.75 & 126 & - & - & - \\
\hline Cue Relevance & 94.75 & 1 & 94.5 & 49.039 & $\mathrm{p} L .001$ \\
\hline Ambiguity & 4.023 & 1 & 4.023 & 6.295 & $\mathrm{p} L .025$ \\
\hline Grps. x Rele. & 9.524 & 1 & 9.524 & 4.942 & $p \leq .05$ \\
\hline Grps. $x$ Amb. & .3809 & 1 & .381 & - & ns \\
\hline Rele. $\mathrm{x}$ Amb. & 8.140 & 1 & 8.140 & 6.87 & $\mathrm{p} L .025$ \\
\hline $\begin{array}{l}\text { Grp. x Rele. } \\
\text { x Amb. }\end{array}$ & .006 & 1 & .006 & - & ns \\
\hline $\operatorname{Error}_{1}$ & 77.101 & 40 & 1.927 & - & - \\
\hline Error $_{2}$ & 25.595 & 40 & .639 & - & - \\
\hline $\operatorname{Error}_{3}$ & 47.47 & 40 & 1.186 & - & - \\
\hline
\end{tabular}


ambiguous cards in the high cue relevance condition, but did not in the low cue relevance condition (see Appendix D). The data also showed that high cue relevance cards elicited more aggressive themes than the low cue relevance cards.

\section{Discussion}

The order of presentation of the discussion follows the order of hypotheses listed on page 12 of this paper. The first hypothesis stated that the subject's overt aggressive behavior would be correlated to the amount of aggressiveness projected on the TAT themes. Although the difference was in the predicted direction the results show that the $\underline{t}$ value of 1.32 was not significantly different from zero at $\mathrm{p} L .05$. This seems to indicate that there is not a direct correlation between overt and fantasy aggression. In other words, it would be difficult in the present study to predict accurately where a person would be placed on the aggressive/non-aggressive dichotomy from the number of aggressive themes written about TAT cards. It seems that more information is needed for an accurate prediction of the relationship between overt and fantasy aggression. The central premise of the present study is that the stimulus properties of the TAT cards are influential in determining the subject's story, and that by determining the influence of the stimulus one can better differentiate aggressive from non-aggressive subjects.

The second hypothesis stated that high cue relevance 
cards would better differentiate aggressive from nonaggressive subjects than low cue relevance cards. The hypothesis was supported by the Group $x$ Cue Relevance interaction, p L.05. These findings are consistent with Kaplan's results that high relevance cards were better able to differentiate hostile from non-hostile subjects than low cue relevance cards. Thus, it seems that by determining the influence of the cards on the subjects' responses, one can better differentiate the two groups.

The present findings are also consistent with the results of James and Mosher (1967). They maintained the notion that predictive accuracy increases as predictor and criterion become more similar. In other words, the ability to differentiate aggressive from non-aggressive subjects should increase as the cue relevance of the cards pulls for aggression. They found that high pull cards were able to discriminate aggressive from non-aggressive subjects based on a sociometric questionnaire. The present findings support the idea that predictive accuracy increases as predictor and criterion become more similar. However, it is impossible to compare directly the present results with those of James and Mosher since they used a specially constructed TAT-like test. The present study's conclusion of the better discriminability of high cue relevance cards contradicts Murstein's (1965) and Saltz and Epstein's (1963) results that low cue cards better discriminate aggressive from non-aggressive 
subjects. With respect to Murstein, it could be that the discrepancy results from the use of different norms in determining the levels of cue relevance. Murstein used the norms based on one of his earlier studies (Murstein, et al., 1961), while the present study used Eron's (1950) norms. However, a comparison of the cards used in the two norms reveals much similarity. Murstein would consider two of the high cue relevance cards in the present study $(8 \mathrm{BM}, 20)$ as medium relevance cards, while the other two high relevance cards $(11,15)$ would also be considered high cue relevance cards by Murstein (1961). Three of the low cue relevance cards used in this study would be considered low cue relevance cards by Murstein (9BM, 14, 2), while the other low relevance card (7BM) would be considered a medium relevance card. Thus, it seems that the discrepant results can not be accounted for by the use of cards that did not reflect high cue relevance.

A possible explanation for the discrepancy with Murstein's results concerns Murstein's selection process for determining hostile and friendly subjects. Murstein defined the hostilefriendly dimension by having subjects rate themselves in relation to peers on the dimension of friendliness. He then assumed that low ratings on the friendliness dimension implied hostility, which the present experimenter believes to be an unwarranted assumption. The subjects might not have represented a true sample of the friendly-hostile dimension. Another explanation that could account for the discrepant 
results was an instructional set condition of Murstein's experiment where he told the subjects to "look your best" (to project a favorable image of themselves). It was under the "look your best" condition that low cue relevance cards were better able to differentiate the hostile from the friendly subjects. The present findings, by using a bipolar dimension of aggression, question Murstein's conclusion that low cue relevance cards discriminate hostile from friendly subjects better than high cue relevance cards.

Saltz and Epstein (1963) found that cards of low cue relevance were best in discriminating hostile from non-hostile subjects. It is difficult to compare the present findings with those of Saltz and Epstein since they used a "specially. constructed TAT-iike test." Thus, it is impossible to compare the level of cue relevance to either Eron's (1950) or Murstein's (1961) norms since the levels of cue relevance were neither based on norms nor even validated. The present study contradicts Saltz and Epstein's results.

The results of the second hypothesis supporf the idea that predictive accuracy increases as the predictor and the criterion become more similar. The results also' support the idea that TAT themes are influenced by the stimulus properties of the cards. Thus, one must consider the stimulus properties of the cards before predictions can be made about the subject's personality characteristics based on responses to those cards. The third hypothesis which stated that high ambiguous 
cards would elicit more aggressive themes than low ambiguous cards was found significant, $\mathrm{p} L .05$. Both aggressive and non-aggressive subjects gave more aggressive responses to high ambiguous cards than low ambiguous cards when ignoring the cue relevance of the cards. Kaplan (1967) also found that high ambiguous cards elicited more aggressive themes from both aggressive and non-aggressive subjects. However, Kaplan found this condition regardless of the level of cue relevance. He reasoned that socially disapproved behavior, such as aggression, finds its expression in ambiguous situations, whether or not the situation pulls for aggressive behavior. The present findings do not support this conclusion, but rather found an Ambiguity $x$ Cue Relevance interaction, $\mathrm{p} L .05$. High ambiguous cards elicited more aggressive themes than low ambiguous cards in the high cue relevance condition, but did not in the low cue relevance condition. It seems that ambiguous cards elicit more aggressive themes only when the cue relevance of the cards pulls for an aggressive theme. The analogous social situation would be that socially disapproved behavior, such as aggression, finds its expression more in ambiguous situations that pull for aggression than in ambiguous situations that do not pull for aggression.

The data does support Kaplan's results and Murstein's (1963) review of the literature that increasing the ambiguity of a card does not lead to greater sensitivity of the instrument to aggression (increase the differentiation of aggressive 
from non-aggressive subjects). This was shown in the analysis of variance where the Ambiguity $x$ Group interaction was not significant.

One implication of these findings is that the subject's response to a TAT card is determined by both the subject's personality and the stimulus properties of the cards. This is supported by the data in that high levels of both ambiguity and cue relevance elicited more aggressive themes than low levels of those stimulus properties. In addition, the evidence supports the idea that predictive accuracy. increases as the predictor and the criterion become more similar. In other words, high cue relevance cards were better able to đifferentiate aggressive from non-aggressive subjects than low cue relevance cards.

The implications of the results are clear for clinicians. The tendency to randomly choose a number of TAT cards to administer to either a clinical patient or research subject and assume that the stories told reflect certain personality characteristics is completely unwarranted. The assumption that aggression can be detected by using low relevance cards to see if they elicit a hostile response also seems questionable since the data failed to reflect any significant differences with these cards. High cue relevance cards, while they elicit more aggression from both aggressive and non-aggressive subjects, also provide for the best dif- . ferentiation between the two groups. However, since the 
differentiation is one of degree rather than one of the absence or presence of aggressive themes in high relevance cards, one must be cautious in assigning subjects to either an aggressive or non-aggressive group without reference to the degree of the aggressive fantasy response. 
CHAPTER III

\section{STUDY II}

The purpose of this study is to examine the relationship between an overt behavior criterion of aggression and both projective and objective test data. study I dealt with the effect of stimulus pull of the TAT cards. Study II is concerned with objective measures of personality factors which may affect both the projective test results and their relationship to overt behavior.

The current study attempts to measure aggressive tendencies objectively. Many attempts have been made to develop objective instruments for the measurement of aggression (Buss and Durkee, 1957; Cook and Medley, 1954; Ganzer and Sarason, 1968; Saltz and Epstein, 1963; Sarason and Winkel, 1966; Zaks and Walters, 1959). Validity studies of many of the above and other inventories developed to measure aggression have not been encouraging (Buss, 1961; Liebowitz, 1968; Megargee and Mendelsohn, 1962; Murstein and Wiens, 1965; and Rabinowitz, 1975).

In addition to questions about the validity of objective measuring instruments used, there are other complications which make difficult the comparison and interpretation of other studies on aggression. Criterion used to divide subjects 
into high and low aggression groups are greatly varied and include sociometric, self-report, or other types of overt behavior such as crime committed, school records, or behavior in a laboratory situation. Many studies use projective tests, such as the TAT, for which there are several different scoring systems of the aggressive content in the thematic stories (Murstein, 1968). Also, many experimenters develop special TAT-like cards rather than using the original cards. Even if a subset of the original 31 TAT cards is used, the number of different combinations possible is in itself discouraging for anyone trying to review and interpret various studies.

The current investigator has tried to design a study which is replicable, and to use measuring instruments which have been successfully used to discriminate subjects in other studies on aggression. One scale which has been used in several studies is the Zaks and Walters Aggression Scale. Zaks and walters (1959) began developing the scale wi.th 33 items described as including the following three types of items :

(a) those dealing with some aspect of aggression as determined by manifest content, e.g., "I often feel like picking a fight with someone"; (b) items related to aggression in an indirect manner, e.g., "Most people get killed in accidents because of their own reckless driving"; and (c) items for which agreement by testee was assumed to denote aggression on theoretical grounds rather than on account of their content, e.g., "I almost never dare to express anger towards people for fear I may lose their love or approval." (Zaks and Walters, 1959, p. 201)

The final scale included 12 items which had success- 
fully discriminated the following: Negro assaultive prisoners from Negro and white control groups of varying socioeconomic levels, high school boys from both adult males and delinquent repeat offenders matched for age, and institutionalized delinquents from "self confessed delinquent" boys attending high school (Zaks and Walters, 1959).

Two validation studies were done by Walters and Zaks (1959). The first study found a significant difference between the scores of frustrated students and nonfrustrated students. The design of the study was based on the assumption that when frustration is induced, aggression will result. The second study involved eight groups of subjects divided on the basis of other group members' rankings of the extent to which each subject displayed aggression in a socially unacceptable manner. Subjects were given the following description to use when ranking other group members:

There are some people who are ruthless and inconsiderate of others in pursuing their aims. They assert themselves in a domineering manner, and try to impose their ideas on other people. They are loudmouthed and argumentative, and defy the standards of their own social group. (Walters and Zaks, 1959, p. 214)

The scores on the Aggression Scale of subjects rated high in aggression (the highest ranking third) were significantly higher than subjects who were rated low in aggression (the lowest ranking third).

The Zaks and Walters Scale of Aggression was one of the 25 inventories Murstein and Wiens (1965) studied using a 
group of male psychiatric patients and a group of normal persons. The Zaks and Walters Aggression Scale was found to differentiate persons within a five point aggressiveness classification system Murstein and Wiens termed "Interpersonal Dimension." "Normals" received the lowest aggression scores, persons classified under "Interpersonal Hostility" (murder, assault, verbalized threat) received the highest scores. others received intermediate scores, including persons classed under "Non-Interpersonal Hostility" (embezzlement, wreckage of property), "Hostility Against Self" (attempted suicide, threats against self) and "Non-Hostile Patients." Murstein and Wiens (1965) also found that the Zaks and Walters Aggression Scale differentiated within a "Special Categorization" which broke down the "Interpersonal Dimension" above into more discreet groups.

Even though none of these studies were replicated, Zaks and walters concluded that the 12-item scale was a valid measure of aggression for discriminating pathologically aggressive subjects from normals and also for discriminating subjects in the normal range (Walters and Zaks, 1959). One hypothesis in the present study predicts that the zaks and Walters Aggression Scale will be able to discriminate between aggressive and non-aggressive prisoners. It is also predicted that there will be a positive relation between fantasy aggression and the behavioral criterion of crime committed. In a review of literature on the effectiveness of TAT, Dhapola (1971) 
concluded that, in most studies, the correlation between fantasy aggression and behavioral aggression is positive, but not high.

Another hypothesis of the present study is that there will be a high correlation between TAT aggressive content and the self-report Aggression Scale. Dhapola (1971) inferred from his review that contrary to the notion that projective techniques reveal underlying deep aggressive trends, they reveal only those trends which the subjects, if willing, can verbalize. Similarly, Murstein (1965, 1968) found a significant difference between hostile and friendly persons (based on judgments of others) only when the subjects' self concept was considered. Subjects with hostile self-concepts projected more thematic hostility than persons with friendly selfconcepts. Kaplan (1967) found high relevant cards able to discriminate groups divided on the basis of a self-report hostility measure. Contradictorily, Saltz and Epstein (1963) found in Design 2 (see below) that the self-report aggression score was positively related to low relevant TAT-like cards, but no relation was found between high relevant cards and self-report aggression.

The current study is also interested in the effect of guilt over hostility on the Aggression Scale and on fantasy aggression. A study done by Saltz and Epstein (1963) was concerned with objectively measured factors of hostility, and guilt over hostility, and their effect on thematic stories. 
Saltz and Epstein's study involved three separate designs. Initially 181 male college students were given self-report inventories including ones on hostility, guilt, and conflict over hostility which they had developed (see Saltz and Epstein, 1963, pp. 471-2, for a more complete explanation of the developmental process).

In Design 1 of the Saltz and Epstein study, self-report hostility and guilt were treated equally, scores were divided at the median into high or low hostility and high or low guilt over hostility and placed into a two by two table. The 20 subjects in each quadrant with the most extreme scores were then picked for data analysis.

In the second design, Saltz and Epstein chose subjects first on the basis of extreme hostility scores. Subjects with the highest 20 self-report hostility scores were then grouped on the basis of self-report guilt scores into high hostility, high guilt; and high hostility, low guilt. From the total subjects tested, the subjects with the lowest 20 self-report hostility scores were chosen and then divided into high and low guilt on the basis of their self report guilt scores.

In Saltz and Epstein's Design 3, guilt was used as the main division. Subjects with the 20 highest and 20 lowest guilt scores were chosen. These two groups were then divided secondarily on the basis of self-report hostility scores. Thus, as in the other two designs there were four groups: 
high guilt, high hostility; high guilt, low hostility; low guilt, high hostility; and low guilt, low hostility.

In all three of the above designs, comparisons were made of thematic stories told to specially-constructed TATlike cards. When subjects were divided for Design 1, an inverse relationship was found between self-report guilt and self-report hostility. That is, high hostility scores were related to low guilt scores, while low hostility scores were related to high guilt scores. Saltz and Epstein (1963) interpreted this finding as supporting the idea that guilt leads to an inhibition of those responses that produce guilt. The current study used the guilt scale developed by Saltz and Epstein and the Zaks and Walters Aggression scale. It was predicted that an inverse relation would exist between these two self-report inventories. There is also some evidence that self-report guilt is inversely related to thematic aggression (Saltz and Epstein, Designs 1 and 3, 1963; James and Mosher, 1967); this is also considered, in addition to the relationship between self-report guilt and overt behavior.

Below is a list of the three hypotheses which this study examines:

1) Self-report guilt is inversely correlated to the self-report aggression scale score, thematic aggression and overt aggression.

2) Self-report aggression should be positively correlated with the amount of fantasy aggression reflected in 
stories elicited by the TAT.

3) TAT aggression scores and self-report aggression scores are positively correlated to type of crime committed (the aggressive prisoners will have higher scores than the non-aggressive prisoners).

\section{Methods}

Subjects

The subjects are the same as in Study I above.

Materials

Eight TAT cards were administered (see Study I for explanation of cards chosen and aggression scoring system used) followed by a 54-item questionnaire including an aggression scale, a guilt scale and a defensiveness scale.

Saltz and Epstein Guilt Scale. The eight-item Guilt Scale administered was the scale used by Saltz and Epstein (1963), to measure negative attitudes toward the expression of hostility. Subjects were asked to mark each item as 1 , Definitely False; 2, Mostly False; 3, Mostly True; or 4, Definitely True. Scores consisted of the sum of the weights after making reversals for oppositely worded items. The possible range of scores was from 8 to 32 .

Zaks and Walters Aggression Scale. The Aggression Scale used in this experiment was originally developed by Zaks and Walters (1959). Subjects were asked to mark each 
stories elicited by the TAT.

3) TAT aggression scores and self-report aggression scores are positively correlated to type of crime committed (the aggressive prisoners will have higher scores than the non-aggressive prisoners).

\section{Methods}

\section{Subjects}

The subjects are the same as in study I above.

Materials

Eight TAT cards were administered (see Study I for explanation of cards chosen and aggression scoring system used) followed by a 54-item questionnaire including an aggression scale, a guilt scale and a defensiveness scale. Saltz and Epstein Guilt Scale. The eight-item Guilt Scale administered was the scale used by Saltz and Epstein (1963) to measure negative attitudes toward the expression of hostility. Subjects were asked to mark each item as 1 , Definitely False; 2, Mostly False; 3, Mostly True; or 4, Definitely True. Scores consisted of the sum of the weights after making reversals for oppositely worded items. The possible range of scores was from 8 to 32 .

Zaks and Walters Aggression Scale. The Aggression Scale used in this experiment was originally developed by Zaks and Walters (1959). Subjects were asked to mark each 
item True or False. Agreement with any item was given a score of one, disagreement a score of zero, so the possible range of scores for the Aggression Scale was zero to 12 .

MMPI K Scale. Included in the questionnaire were 27

items from the MMPI $\mathrm{K}$ Scale to determine if the subjects were responding in an unduly defensive and overly self-favorable way. Persons receiving an extremely high $\mathrm{K}$ score are described as being highly defensive, minimizing or understating problems in social and emotional adjustment (Marks and Seeman, 1963, p. 307).

Saltz and Epstein included the MMPI I Scale in their study to "discard unduly defensive subjects, to compare the experimental groups on defensiveness, and to provide descriptive information for comparison with future studies" (Saltz and Epstein, 1963, p. 472). However, a high I score can be interpreted to mean either the person is very scrupulous or is being deceitful in describing high moral standards, self control and social conformity (Marks and Seeman, 1963, p. 307). Also, a deliberate attempt to slant test answers to create a special impression of freedom from any psychological problems or character faults usually results in an elevated $L$ only for persons of limited sophistication or proficiency in dealing with psychological tests (Dahlstrom, et al., 1972, p. 158). More sophisticated test subjects usually avoid the unbelievable and homely virtues of the $\mathrm{I}$ Scale and readily acknowledge these common defects. But when presented the 
more subtle self enhancements provided by the $\mathrm{K}$ Scale, the subject is able to rationalize and equivocate in such a way as to give his self the benefit of doubt, thus earning an elevated K score (Dahlstrom, et al., 1972).

\section{Procedure}

The procedure was the same as for Study I. After the TAT stories had been collected, the questionnaire was distributed and the following instructions were given:

On the first part of this questionnaire, read each item carefully and then answer either true or false according to your first impression. You may not completely agree or disagree with an item, but if you agree with an item slightly more than you disagree, answer true; if you disagree with an item slightly more than you agree, answer false. Go through the items quickly without spending a great deal of time on any one item. Your first impression after reading an item is what we want. On the second part, read each item and then check the category which most closely gives your opinion: Definitely False, Mostly False, Mostly True, or Definitely True. Again, your first impression is best, go through the items as quickly as you can.

In order to permit data analysis, the same number appeared on the top of the pages a given subject used for writing the TAT stories and on the questionnaire answered by that subject.

Results

Hypothesis 1

To test the hypothesis that self-report guilt is inversely correlated to self-report aggression, a Pearson 
product-moment correlation was calculated. A low, but significant correlation was found between the self-report Guilt Scores and self-report Aggression Scores $\underline{\underline{r}}=-.37, \underline{z}=2.37$, $\mathrm{p} / .01)$. No significant correlation was found between selfreport guilt and thematic aggression $(\underline{r}=-.05)$. Using a point-biserial correlation, no significant correlation was found between group and self report guilt $(\underline{r}=.13)$.

Hypothesis 2

No significant positive correlation was found between the zaks and Walters Aggression Score and the amount of aggression projected in the TAT stories. Taking into account card relevancy did not produce different results. The Pearson product-moment correlations were as follows: self-report Aggression Score and TAT Aggression Score, $\underline{r}=.12$; high relevant cards only, $\underline{\underline{r}}=.03$; low relevant cards only, $\underline{\underline{r}}=.17$. None of these correlations are significantly different from $\underline{r}=0$.

Hypothesis 3

Contrary to the hypothesis, no significant positive correlation was found between crime committed laggressive or non-aggressive) and either self-report aggression or TAT aggression. The point-biserial correlation between group and self-report aggression was .21 $(\underline{t}=1.36, \mathrm{p} T .10)$. Table III gives the percentage of each group agreeing with the 12 items of the Zaks and Walters Aggression Scale. Only five 
TABLE III

PERCENTAGE OF AGGRESSIVE AND NON-AGGRESSIVE

GROUPS AGREEING WITH EACH ITEM OF THE

ZAKS AND WALTERS AGGRESSION SCALE*

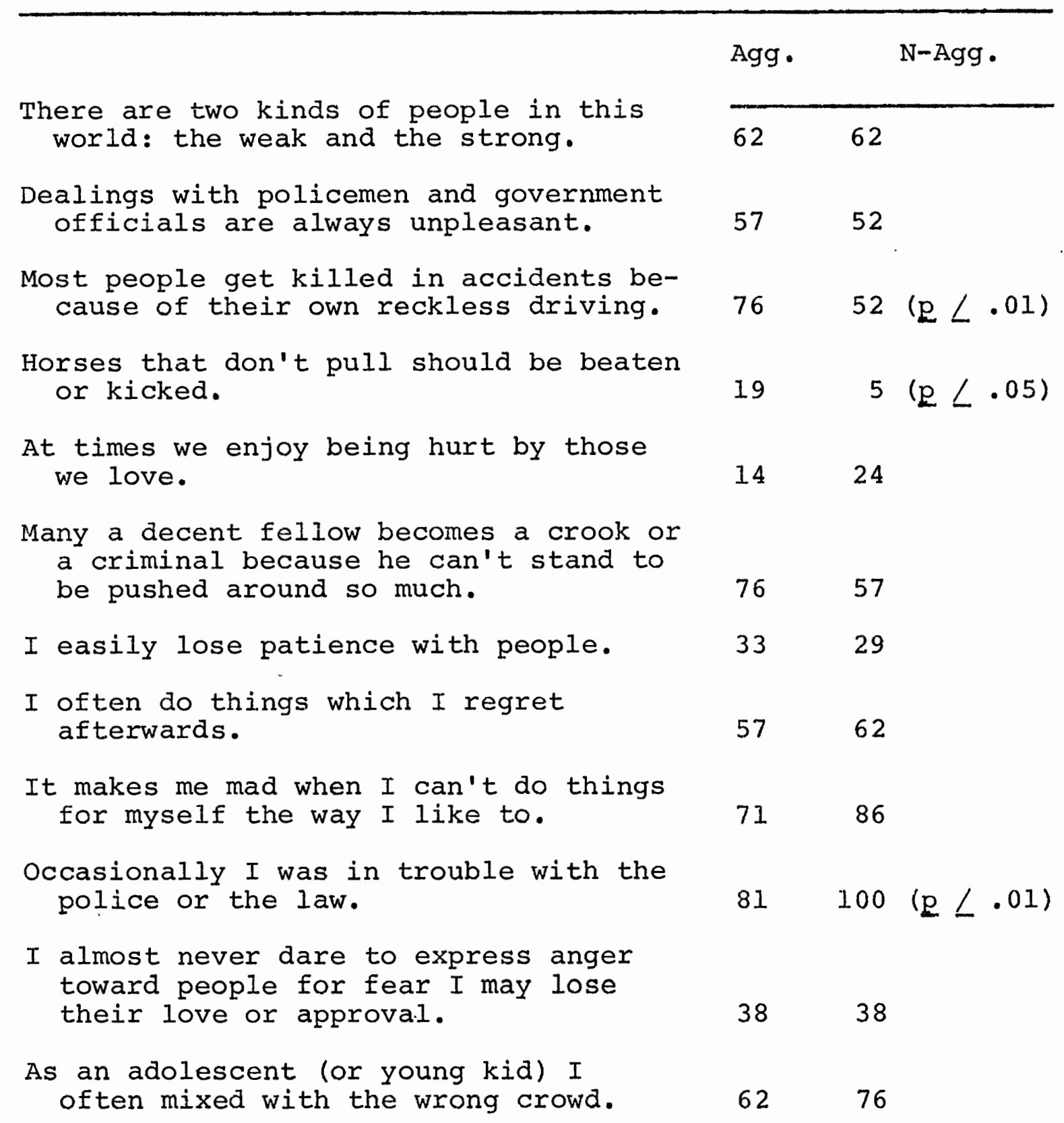

*Agreement with any item is given a score of one, disagreement a score of zero. 
items were agreed to by a larger percentage of the aggressive group (there was a significant difference between the proportions for the two groups on only two of these items). On two items the percentage of agreement was exactly the same for both groups and five items were agreed to more often by the non-aggressive group (one of these items having a significant difference between the proportions for the two groups opposite to the expected direction).

The point-biserial correlation between crime group and TAT aggression score was $\underline{r}_{\mathrm{pb}}=.23, \underline{t}=1.53$. When card relevancy was considered, however, there was a significant correlation between crime group and the high relevant cards $\left(\underline{r}_{\mathrm{pb}}=.35, \underline{\mathrm{t}}=2.38, \mathrm{p} L . .05\right)$.

MMPI K Score

No significant difference on the MMPI $\mathrm{K}$ Scale was found between the two groups of prisoners $(\underline{t}=.91)$. None of the subjects had $\mathrm{K}$ scores which were unduly high and warranted discarding the data. There was a correlation of -.72 between the $K$ scores and the self-report Aggression Scores $\underline{z}=4.61$, $\mathrm{p}(.001)$.

The mean scores and range of scores on the TAT, zaks and Walters Aggression Scale, Saltz and Epstein Guilt Scale and MMPI $\mathrm{K}$ Scale are given in Table IV for each group, aggressive and non-aggressive. 
TABLE IV

MEAN SCORE AND RANGE FOR AGGRESSIVE AND NONAGGRESSIVE GROUPS ON EACH OF THE FOUR MEASUREMENTS USED IN STUDY II

\begin{tabular}{lrrrr}
\hline & \multicolumn{2}{c}{ Aggressive } & \multicolumn{2}{c}{ Non-aggressive } \\
\cline { 2 - 5 } & \multicolumn{1}{c}{ Mean } & Range & Mean & Range \\
\cline { 2 - 5 } & 6.5 & $0-10$ & 6.4 & $3-10$ \\
Self-Report Aggression & 21.8 & $12-27$ & 20.8 & $10-29$ \\
Self-report Guilt & 9.9 & $3-22$ & 11.1 & $5-19$ \\
Defensiveness Scale & 7.4 & $0-16$ & 5.6 & $0-9.5$ \\
Thematic Aggression & & & &
\end{tabular}

Discussion

The correlation of -.37 between self-report aggression and self-report guilt supports part of the first hypothesis (however, this is a modest correlation accounting for only approximately $14 \%$ of the variability). No statistically significant correlation was found between self-report guilt and thematic or overt aggression. It does not seem that the results of this study support the hypothesis that guilt over. hostility has an inhibitory effect on either fantasy aggression or aggressive behavior. Thus, the current study, using TAT cards, does not confirm either the James and Mosher study (1967) where guilt (as measured by a forced choice hostility- 
guilt inventory) was found to have an inhibitory effect on aggressive content of thematic stories told to low relevant TAT-like cards, or the Saltz and Epstein study (1963) where self-report guilt was found to be negatively correlated to high relevant TAT-like cards. It is interesting to note that of the three measures of aggression in the current study (selfreport, fantasy and overt behavior) the only measure with any significant relation to the self-report guilt was the other self-report measurement.

Considering the second hypothesis, no correlation was found between the self-report aggression score and the thematic aggression score. Contrary to the theories of Dhapola (1971) and Murstein $(1965,1968)$, this study did not find that the prisoners presented consistent aggressive or non-aggressive tendencies on both the objective and projective measures of aggression administered for this study. Rather, the results seem to support Mischel's (1971) position that the stimulus environment (in this case, if it is an objective self-report measure, a projective technique or a behavioral measure) is more important in determining response than the subject's actual disposition. Thus, the Zaks and Walters Aggression Scale and the TAT cards seem to be measuring different aspects of the subject's personality and only stories told to the high relevant cards seem to be related to the behavioral criterion. It does not seem that the zaks and Walters Aggression Scale is a valid instrument if the purpose is to differentiate 
groups of prisoners divided by crime committed on the basis of Wilds' (1973) classification system. In fact, only five of the items were agreed to more often by the aggressive prisoners and only two of the items significantly differentiated the two groups in the predicted direction. On one item there was even a significant difference between the two groups opposite to the predicted direction. The level of negative correlation with the defensiveness scale suggests that the zaks and Walters Scale may actually be measuring the willingness to endorse socially undesirable traits (i.e., aggressive tendencies) or consciousness of aggressive feelings rather than actual behavioral tendencies toward aggression or the subject's actual aggressive/non-aggressive self concept. This interpretation may be consistent with some of the findings of the studies on the Zaks and Walters Aggression Scale discussed in the introduction. Frustrated subjects may be simply more willing to admit to aggressive feelings rather than actually being more aggressive, the zaks and walters Scale may have been measuring a greater willingness of psychiatric patients or addicts to admit to aggressive feelings than normals rather than the actual aggressive behavioral disposition.

There is also the possibility that the negative correlation was affected by subjects' acquiescence, since answering true to all questions would have resulted in a high self-report aggression score and a low defensiveness score. 
However, the importance of agreement response sets on selfreport devices has been questioned (Rorer, 1965; Mischel, 1971) and the present experimenter doubts if acquiescence alone accounts for the degree of negative correlation found between the two scales.

Examining the results of Study II, and the lack of significant differences between the two groups (except for the modest correlation on the high relevant cards), two hypotheses are suggested: either there is actually little difference in personality traits between the two groups of prisoners or the self-report inventories used are not valid measures for the differences that do exist. Deciding between these alternatives would seem to have important implications if one desires to predict the probability of future aggressive or non-aggressive behavior which is of practical importance in determining the most effective rehabilitation program for a given inmate.

Residents of the Oregon State Women's Correctional Institution suggested that a more useful system for dividing prisoners so that the probability of group personality differences would be increased, would be on the basis of a comparison of the situation surrounding the crime committed. They felt the important variable was whether the crime was premeditated or if it was the result of an emotionally charged situation (a crime of passion) or simply a matter of being in the wrong place at the right time. 
The current study was definitely not designed to test Mischel's (1971) conclusion that recent studies suggest it is possible to predict important behaviors better by knowing the conditions of a person's life than by inferring his traits and motives. Neither do the present results negate the possibility that his conclusion is correct. In words similar to those reported by Mischel (1971, p. 150), it may be possible to make a more accurate prediction of past (or future) aggressive behavior if one has information about the subjects' access to available housing and job opportunities rather than on their personality traits.

The current experimenter suggests that the most accurate prediction of aggressive behavior would result from a consideration of the ecological variables referred to above, in combination with personality measurements including a range of objective and projective instruments, including high relevant TAT cards but probably not either the zaks and Walters Aggression Scale or Saltz and Epstein's Guilt Scale. More extensive studies are needed to determine more exactly the relationship between specific situational and personality variables and aggressive behavior. 
CHAPTER IV

\section{STUDY III}

Much of the beginning research in trait psychology was based on the assumptions that broad trait structures exist and would lead people to behave consistently; in other words, an individual's position on one or more personality dimensions would be relatively stable across testing situations and time periods (if the test were reliable). In more recent years a great deal of research has shown that performances on all trait measures and behavior in general are affected by a variety of stimulus conditions, and can be modified by numerous environmental changes (Mischel, 1971, p. 147). Study III investigates the effect of a variety of stimulus conditions (a comparison of self-report trait measures of aggression, guilt, and defensiveness with a projective measure of aggression; and the comparison of TAT cards of varying relevance and ambiguity) on the prediction of overt behavior (type of crime committed: aggressive or non-aggressive). In addition to information on the stimulus properties of cards (Study I) and the subjects' self-report data (Study II), some personal background data was gathered from the subjects. Study III was completely exploratory with the purpose of determining if the two groups could be more accurately 
differentiated by combining the three types of data (objective, projective and personal history). Also of interest was determining if one of the three types of information would be significantly better than the other two in differentiating the two groups. Mischel (1971) suggests that the stimulus environment (i.e., stimulus properties of the cards) are probably more important in determining test response than the subject's actual disposition and that self reports may or may not be closely related to other indices of the person's non-test behavior.

Method

Subjects

The subjects were the same inmates that participated in Studies I and II $(\underline{N}=42)$.

Materjals

In addition to the data of Studies I and II, the subjects were required to fill out a personal data sheet (see Appendix E), which included age, educational level, present crime, previous crimes committed, time spent of current sentence at time of testing, and total other time spent in adult correctional institutions for previous crimes.

\section{Procedure}

The procedure was the same as for Studies I and II. In addition, Personal data was requested after the subjects 
completed the self-report questionnaire. When all materials had been collected, a brief explanation of the thesis was given and any questions the prisoners had were answered.

A stepwise discriminant analysis was used on all the variables to compute a set of linear classification functions. The program chooses the independent variables in a stepwise manner according to predetermined statistical criteria, and a variable is deleted when its $E$ becomes too low. Using these functions and the prior probabilities, the posterior probabilities of each case belonging to each group (in this case aggressive or non-aggressive) is computed (Dixon, 1974).

\section{Results}

A stepwise discriminant analysis was done on ten variables: the thematic aggression score on the high relevant/ high ambiguous TAT cards, high relevant/low ambiguous cards, low relevant/high ambiguous cards, and low relevant/low ambiguous cards; the Zaks and Walters Aggression Scale Score; the self-report guilt score; the defensiveness score; previous total time in adult correctional institutions (excluding current time); educational level; and age. Amount of time spent in prison of the current sentence was eliminated from the analysis because it was found to discriminate between aggressive and non-aggressive subjects on an a priori basis. It was found that subjects who had committed violent crimes had longer sentences due to the nature of their crimes than 
those who had committed crimes that were not violent.

Table $\mathrm{V}$ gives the Aggressive and Non-aggressive group means and ranges for the personal data collected in study III. Using the stepwise discriminant analysis, the variable which most effectively differentiated the aggressive from the non-aggressive subjects was the aggression score for the high cue relevance/high ambiguous cards $\underline{\underline{U}}=.90, \underline{F}(1,40)=4.25$, p (.05). The function provided by the discriminant analysis after the first step would predict that a subject was from the aggressive group if he received a score over the grand mean of 2.75 on the high cue relevance/high ambiguous cards.

TABLE V

MEAN VALUE AND RANGE FOR THE AGGRESSIVE AND NONAGGRESSIVE GROUPS ON THE PERSONAL DATA

GATHERED FOR STUDY III

\begin{tabular}{|c|c|c|c|c|}
\hline \multirow[b]{3}{*}{$\begin{array}{l}\text { Length of current } \\
\text { sentence served } \\
\text { (months) }\end{array}$} & \multicolumn{2}{|c|}{ Aggressive } & \multicolumn{2}{|c|}{ Non-aggressive } \\
\hline & Mean & Range & Mean & Range \\
\hline & 12.5 & $1-49$ & 7.7 & $1-27$ \\
\hline $\begin{array}{l}\text { Total past time in } \\
\text { prison (months) }\end{array}$ & 23.1 & $0-104$ & 14 & $0-69$ \\
\hline $\begin{array}{l}\text { Highest grade } \\
\text { completed }\end{array}$ & 10.4 & $7-15$ & 11.0 & $7-16$ \\
\hline Age & 29.4 & $19-43$ & 29.5 & $20-45$ \\
\hline
\end{tabular}


Using just that one bit of information, there would be 24 subjects correctly labeled and 18 misses.

The second variable entered was the aggression score for the high cue relevance/low ambiguous cards, the third was self-report guilt, the fourth was the defensiveness score, the fifth was the TAT aggression score for low cue relevance/ low ambiguity, and the sixth was past time in prison. After the sixth step, $74 \%$ of the inmates were correctly classified: 31 hits and 11 misses $\underline{U}=.74, \underline{E}(6,35)=2.04, .107 \mathrm{p} 7.05)$. Steps seven through ten decreased the U-statistic by only .01 and the $F$ values were not significant ( 7 .10).

It is interesting to note that on step 7 with the addition of self-report aggression as new information, the percentage of correct predictions decreased from $74 \%$ to $67 \%$. This reduction in percent of correct predictions is an example of Rao's paradox, when additional information actually decreases the accuracy of prediction (Healy, 1969, p. 411). The variables included in steps eight and nine were the aggression score for low relevant/high ambiguous cards and education level, respectively. Age did not meet the statistical requirements for inclusion in the analysis.

\section{$\underline{\text { Discussion }}$}

One objective of Study III was to determine whether the stimulus properties of the cards, self-report data, or information concerning the subjects' background is the most 
important variable in differentiating the prisoners on the basis of crime committed. In the stepwise discriminant analysis the aggression score for the high cue relevance/high ambiguous condition was the most effective variable and the aggression score for the high cue relevance/low ambiguous condition was the second most powerful variable in discriminating -aggressive from non-aggressive subjects. Thus, it seems that in the current study the stimulus properties of the cards are the most important consideration in the prediction of group membership (aggressive or non-aggressive). This is consistent with Mischel's (1971) position that the stimulus condition is an important consideration when evaluating test response in relation to non-test behavior.

Scores of two of the subjects' self-report data were the next most powerful variables: self-report guilt and selfreport defensiveness were the third and fourth bits of information added to aid in the discrimination of the two groups. However, there is some question about the relationship between these scores and the prediction of overt behavior since the $\underline{F}$ values for these steps did not reach significance ( $L$ L .05). Therefore, the increased accuracy of prediction gained by the addition of these measures could be the result of chance rather than an actual relationship between the specific test scores and the behavioral criterion.

The personal data gathered in Study III was of little use in discriminating aggressive from non-aggressive subjects. 
Past time in prison was included in the sixth step, education level in the last step and age was deleted from the linear function.

The main purpose of Study III was to determine whether the combined data of Studies I and II, with the addition of some personal background data, could accurately differentiate aggressive from non-aggressive subjects. The results of the study on this issue are questionable. Discrimination of the aggressive from the non-aggressive subjects was improved by adding the self-report guilt and defensiveness scores, the low relevant/high ambiguous TAT scores, and past time spent in prison to the high cue relevance conditions: the percentage of correct classification improved from $69 \%$ to $74 \%$. However, as reported earlier, the $\underline{F}$ values for these levels did not reach significance. Therefore, the effect of these variables on the increased accuracy of the differentiation of aggressive subjects from non-aggressive subjects could be the result of chance.

One implication of the results of the stepwise discriminant analysis done for Study III is that the stimulus value of the cards is a very important aspect in determining test response and must be considered in the process of predicting overt behavior. However, validation studies are needed to test the usefulness of the aggression score for high relevant/ high ambiguous TAT cards and their superiority over other types of test stimuli in predicting overt aggressive behavior 
defined in terms of crime committed and using other behavioral criteria. 
REFERENCES

Buss, A. H. The Psychology of Aggression. New York: Wiley, 1961 .

Buss, A. H. \& Durkee, A. An Inventory for assessing different kinds of hostility. Journal of Consulting Psychology, 1957, 21, 343-34 $\overline{9}$.

Cofer, C. H. \& Appley, M. H. Motivation: Theory and Research. New York: John Wiley and Sons, Inc., 1964.

Cook, W. W. \& Medley, D. M. Proposed hostility \& pharisaicvirtue scales for the MMPI, Journal of Applied Psychology, 1954, 38, 414-418.

Dahlstrom, W. G., Welsh, G. S. \& Dahlstrom, I. E. An MMPI Handbook. Vol. 1. Minneapolis: University of Minnesota Press, 1972.

Dhapola, T. S. The effectiveness of TAT as a measure of aggression: a review. Indian Journal of Psychology, $1971, \underline{46}, 319-328$.

Dixon, W. J. (Editor). BMD: Biomedical Computer programs. Berkeley: University of California Press. 1974, 233254 .

Eron, I. D. A normative study of the TAT. Psychol. Monogr., $1950, \underline{64}$, No. 9 .

Eron, I. D. Responses of women to the TAT. Journal of Consulting Psychology, 1953, 17, 269-282.

Ganzer, V. J. \& Sarason, I. G. Interrelationships among hostility, experimental conditions and verbal behavior. Journal of Abnormal Social Psychology, $1964,68,79-84$.

Healy, M. J. R. Rao's paradox: concerning multivariate tests of significance. Biometrics, 1969, 25, (2), 411.

James, P. \& Mosher, D. Thematic aggression, hostility-guilt, and aggressive behavior. Journal of Projective Techniques \& Personality Assessment, 1967, 31, 61-67.

Kagan, J. The stability of TAT fantasy and stimulus ambiguity. Journal of Consulting Psychology. 1959, 23, 266-271. 
Kaplan, M. The effect of cue relevance, ambiguity, and selfreport hostility on TAT responses. Journal of Projective Technigues \& Personality Assessment, 1967, 31, 45-50.

Liebowitz, G. Comparison of self-report and behavioral techniques of assessing aggression. Journal of Consulting and Clinical Psychology, 1968, 32, 21-25.

Lindzey, G. Projective Techniques and Cross-Cultural Research. New York: Appleton, 1961.

Lorenz, K. On Aggression. New York: Bantam Books, Inc., 1963.

Marks, P. \& Seeman, W. The Actuarial Description of Abnormal Personality: An Atlas for Use with the MMPI. Baltimore: Wililams \& Williams, 1963.

Megargee, E. I. \& Cook, P. The relation of TAT and inkblot aggressive content scales with each other and with criteria of overt aggressiveness in juvenile delinquents. Journal of Projective Techniques \& Personality Assessment, 3I, 48-60.

Megargee, E. I. \& Mendelsohn, G. A. A cross-validation of 12 MMPI indices of hostility and control. Journal of Abnormal and Social Psychology. 1962, 65, 431-438.

Mischel, W. Introduction to Personality. San Francisco: Holt, Rinehart \& Winston, Inc., 1971, 132-152.

Murray, H. A. Thematic Apperception Test Manual. Cambridge: Harvard University Press, 1943.

Murstein, B. I. Theory \& Research in Projective Technigues. New York: Wiley, 1963 .

Murstein, B. I. Projection of hostility on the TAT as a function of stimulus background, and personality. Journal of Consulting and Clinical Psychology, 1965, $29,43-48$.

Murstein, B. I. Effects of stimulus, background, personality, and scoring systems on the manifestation of hostility on the TAT. Journal of Consulting \& Clinical Psychology, $1968,32,355=365$.

Murstein, B. I., David, C., Fisher, D., \& Furth, H. The scaling of the TAT for hostility by a variety of scaling methods, Journal of Consulting Psychology, 1961, 25, 497-504. 
Murstein, B. I. \& Wiens, A. N. Diagnostic and actuarial correlates of thematic and questionnaire measures of hostility. Journal of Projective Techniques \& Personality Assessment, 1965, 29, 341-347.

Mussen, P. H. \& Naylor, H. K. The relationship between overt and fantasy aggression. Journal of Abnormal Social Psychology. 1954, 49, 235-240.

Rabinowitz, A. Hostility measurement and its relationship to fantasy capacity. Journal of Projective Techniques \& Personality Assessment, 1975, 39, 50-54.

Rorer, I. G. The great response-style myth. Psychological Bulletin, 1965, 63, 129-156.

Saltz, G. \& Epstein, S. Thematic Hostility and guilt responses as related to self reported hostility, guilt, and conflict. Journal of Abnormal \& Social Psychology, 1963, 67, $469-479$.

Sarason, Irwin G. \& Winkel, G. H. Individual differences among subjects and experimenters and subjects' selfdescriptions. Journal of Personality \& Social Psychology. $1966, \underline{3}, 44 \overline{8-457}$.

Stone, H. The TAT aggressive content scale. Journal of Projective Techniques, $1956,20,445-452$.

Tyler, I. Tests and Measurements, Englewood Cliffs: Prentice Hall Inc., 1963.

Walters, R. H. \& Zaks, M. S. Validation Studies of an aggression scale. Journal of Psychology, 1959, 47, 209-218.

Wilds, C. E. Evaluation of a method of predicting violence in offenders. Criminology: an Interdisciplinary Journal. $1973,11,427$.

Zaks, M. S. \& Walters, R. H. First steps in the construction of a scale for the measurement of aggression. Journal of Psychology, 1959, 47, 199-208. 
APPENDIX A

WILDS' (1973) CLASSIFICATION SYSTEM

Violent Crimes

1. A.ll forms of criminal homicide

2. Rape (not statutory)

3. Robbery

4. Assault \& battery

5. Resisting arrest with the use of force

6. Kidnapping-abduction

7. Arson

Non-violent Crimes

1. Burglaries

2. Shoplifting, larceny, theft (cars included)

3. Forgery, uttering, counterfeiting

4. Embezzlement, cheating, fraud

5. Buying, receiving, and possession of stolen property

6. Vagrancy, drunkenness, gambling

7. Corruption of morals of a minor, sodomy, adultry, fornication, bastardy, public indecency, statutory rape, maintaining a house of prostitution

8. Narcotics, liquor and drug law offenses

9. Disorderly conduct

10. Traffic and motor vehicle law violations 
You are participating in a study designed to determine the typical stories told to pictures by inmates. A number of pictures will be shown on the screen. You will have up to twenty seconds to look at the picture and then five minutes to make up a story about it. You have one page for each story. Your task is to make up as dramatic a story as you can for each picture. You are to tell what led up to the event shown in the picture, describe what is happening at the moment, what the characters are feeling and thinking and then give the outcome. Write your thoughts as they come to your mind; literary masterpieces are not required. Please do not compare stories. You are allowed a maximum of five minutes on each card. You will be warned when four minutes have elapsed so that you can wrap up your story. 
APPENDIX C

I

have freely volunteered to

participate in the present experiment. It is my understanding that my participation in the experiment will not influence my status at the oregon state Penitentiary. The materials obtained will be used only for the purpose of the experiment, and that the prison officials will not have access to them. I also understand that I may withdraw from the experiment at any time, and that after I complete the experiment $I$ will be paid $\$ 1.00$ for my participation. 


\section{APPENDIX D}

Group x Cue Relevance Interaction*

TAT

Aggression Score

TAT

Aggression Score

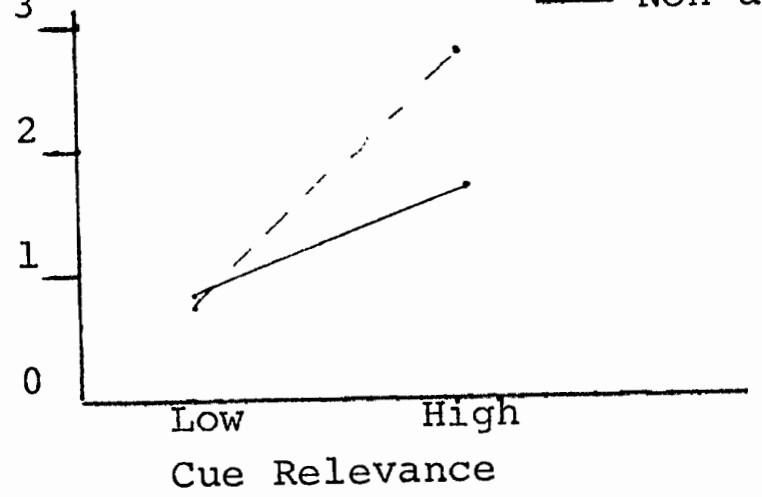

Ambiguity $x$ Cue Relevance Interaction*

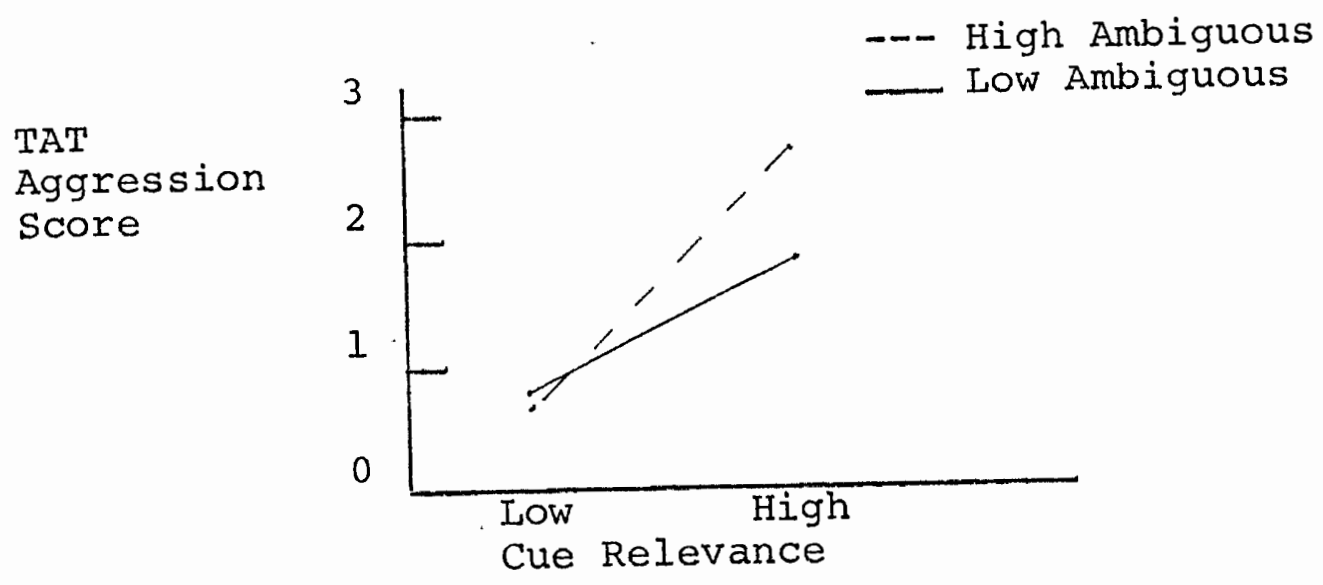

$* \mathrm{p} L .05$ 


\section{APPENDIX E}

Age:

Highest grade completed in school:

Crime for which you are now serving a sentence:

How much of this sentence have you served? year (s)

$\operatorname{month}(\mathrm{s})$

Have you ever been sentenced to an adult correctional institution before?

$$
\text { Yes_ No N__ }
$$

If Yes, please list crime for which sentenced and total length of sentence served:

CRIME $\quad$ Years SENTENCE




\section{APPENDIX F}

\section{RESULTS OF STEPWISE DISCRIMINANT ANALYSIS}

\section{Results of step 1:}

Variable entered (VI): High relevant/high ambiguity

$$
\underline{U}=.90 \quad \underline{\mathrm{E}}=4.25 \quad \underline{\mathrm{df}}=1.40 \quad \mathrm{p} L .05
$$

Formulas given for predicting group:

$$
\begin{aligned}
& \mathrm{A}= 1.25919(\mathrm{VI})+ \\
&-2.74683 \\
& \mathrm{~N}= .86397(\mathrm{VI})+ \\
&-1.65997 \\
& \text { If } \mathrm{A} \backslash \mathrm{N} \text { "Aggressive group" is predicted } \\
& \text { If } \mathrm{A} \perp \mathrm{N} \text { "Non-aggressive group" is predicted. }
\end{aligned}
$$

Number of cases classified into group:

A $\quad \mathrm{N}$

$\begin{array}{llll}\text { Actual } & \text { A } & 15 & 6 \\ \text { Group } & \text { N } & 12 & 9\end{array}$


APPENDIX F (continued)

Results after step 6:

lst variable entered (VI): High relevant/High ambiguity

2nd variable entered (V2): High relevant/Low ambiguous

3rd variable entered (V3): Self-report Guilt Score

4 th variable entered (V4): Defensiveness Score

5 th variable entered (V5): Low relevant/Low ambiguous

6 th variable entered (V6): Past time spent in prison

$$
\underline{U}=.74 \quad \underline{F}=2.04 \quad \underline{\mathrm{df}}=6,35 \quad .107 \mathrm{p} 7.05
$$

Formulas given for predicting group:

$$
\begin{array}{r}
\mathrm{A}=\quad 1.75558(\mathrm{~V} 1)+ \\
.87507(\mathrm{~V} 2)+ \\
-1.48812(\mathrm{~V} 3)+ \\
.14875(\mathrm{~V} 4)+ \\
.17914(\mathrm{~V} 5)+ \\
2.09367(\mathrm{~V} 6)+ \\
-29.33838 \\
\mathrm{~N}=\quad 1.36254(\mathrm{VI})+ \\
.45768(\mathrm{~V} 2)+ \\
-1.02981(\mathrm{~V} 3)+ \\
.12782(\mathrm{~V} 4)+ \\
.29448(\mathrm{~V} 5)+ \\
1.88295(\mathrm{~V} 6)+ \\
-24.18812
\end{array}
$$

If A $7 \mathrm{~N}$ "Aggressive group" is predicted

If $A$ L. $N$ "Non-aggressive group" is predicted.

Number of cases classified into group:

A $\quad \mathrm{N}$

$\begin{array}{llll}\text { Actual } & \text { A } & 15 & 6\end{array}$

$\begin{array}{llll}\text { Group } & N & 5 & 16\end{array}$

